The appeal terms the former "a threatened momentous alteration," whilst it considers the latter a "special sacrifice" of panel practitioners. It urges all to join the Union at once and by so doing place it in funds to fight the enemy.

What are the true facts on these two points? 1. That the Commission notified last March to the British Medical Association that it had "no changes of any kind under consideration for adoption during the currency of the present year." This was published in the Panel Medico-Political Union's periodical. 2. That on July 14th last Parliament passed the Estimates for Civil Services, 1915-16, which included the $2 s .6$. grant for 1916 (Class VII., pages 12,16 , and 20). That being so, this "stirring appeal" for money has been issued either in total ignorance of these two facts, thus marking the Union as an unreliable body; or with the deliberate intention and hope to trade on the probable ignorance of the average panel practitioner. This circular goes on to state that the Union obtained recently certain delayed payments. Shortly, probably, we shall hear that it has obtained the payment of this $2 s .6 d$. per head grant.

At this time, when every medical practitioner, even if he can only crawl into a motor or carriage, is trying to repay in part his debt to his country, this appeal for funds for an aggressive campaign is greatly to be deprecated, especially when it is based on fiction. Panel practitioners will do well to consult some reliable and recognised authority for confirmation of "facts" before they part with their hardly earned guineas in response to any " stirring appeals" that may reach them.

I am, Sir, yours faithfully,

Hove, August 17th, $1915 . \quad$ E. RowlaND FothergILL.

\section{TONSILLECTOMY IN RELATION TO ACUTE RHEUMATISM.}

To the Editor of THE LANCET.

SIR,-I do not think Dr. P. R. Cooper, who writes in THE LANCET of July 24th, need blame himself because his patient had acute rheumatism after tonsillectomy, although, as a rule, if there is any healthy tonsil present it should be left. That removal of chronically diseased tonsils should put the patient in a state of liability to contract acute rheumatism is a theory which, being contrary to experience, should be received with much hesitation. On the contrary, I have always looked upon tonsillitis as both primarily rheumatic and provocative of further attacks of rheumatism if the tonsillar inflammation becomes chronic. These remarks apply principally to recurrent attacks of the follicular form of the disease in which the crypts are stuffed with creamy or cheesy material in which streptococci generally abound. The sooner these sources of septic infection are got rid of the better, and through a long experience with such cases I have never had occasion to regret having advised operation. In heart cases I consider the presence of tonsils such as I have described a distinct source of danger and one calling for prompt treatment if the condition of the heart will allow it. In early and mild cases the galvanic cautery applied to the crypts will at times do all that is necessary.

In conclusion I may quote Sir William Osler on the subject: "In patients with diseased tonsils in whom rheumatic fever has occurred removal is advisable and should be always complete" ("Principles and Practice of Medicine," eighth edition, p. 380). "A not infrequent precursor of rheumatic fever"; and, most important as bearing on the question of tonsillectomy, "It is comparable to the removal of any local focus of infection which is causing general symptoms.'

I am, Sir, yours faithfully,

Harley-street, W., August 7th, 1915.

$$
\text { Charles W. Chapman. }
$$

THE LATE MR. EDMUND OWEN.

$$
\text { To the Editor of THE LaNCeT. }
$$

SIR,-I have read with much interest the obituary notice of Mr. Edmund Owen which you published in your issue of July 3lst. I should be glad, however, if you would kindly supplement it in your next issue by mentioning the eminent services which our lamented friend rendered to the French Hospital, and for which he received the Cross of the Legion of Honour from the hand of M. Emile Loubet when, as President of the French Republic, he visited the hospital in 1903.

Mr. Edmund Owen succeeded Sir W. MacCormac as surgeon to the French Hospital in December, 1901, and up to his death always manifested the liveliest interest in the hospital; many are the patients who have benefited by his talent and devotion. On several occasions at our annual banquets he gave expression to the sympathy which he had for the French Hospital and the patients whom he had under his care.

But if he loved the hospital, everybody here loved him; his death leaves a great void, and we shall ever regret the loss of a man who combined with the highest professional capacity a character of lofty personality, straightforwardness, and affectionate devotion.

\section{I am, Sir, yours faithfully,} ARTHUR BAUME, President of the Committee of the French Hospital. President of the Committee of
Shaftesbury-avenue, W.C., August 10th, 1915.

\section{AMPUTATIONS FOR GANGRENE.}

To the Editor of THE LANCET.

SrR,-Having recently had the opportunity of observing a considerable number of cases where amputation was performed on limbs crushed and burnt in the Gretna railway disaster, I can endorse everything Mr. A. Marmaduke Sheild says in THE LANCET of to-day's date as to drastic measures. I am glad to say that in no case was it thought expedient to resort to the operation of Antyllus.

I am, Sir, yours faithfully,

W. D. ANDERSON,

August 7th, 1915 Medical Officer in Charge, Cumberland Infirmary.

\section{HOSPITAL TREATMENT $V$. LUNACY TREATMENT.}

To the Editor of THE LANCEr.

SIR,-I must thank Sir George Savage for his friendly commentary in your issue of July 31st. He has himself long advocated the provision of reception houses where voluntary patients could enter for treatment in the early stages. This solution has never yet had a trial, because no places of the kind as yet exist within reach of the great mass of the community whose means are limited. In such hospitals general practitioners could become acquainted with the nature of the earliest symptoms and the best way to treat them, and receive a training which would be invaluable for the prevention of insanity. This is not a theoretical but a very practical proposal. 